\title{
FRACTURE IN CHILDHOOD PARAPLEGIA
}

\author{
By Gordon C. Robin, M.B., F.R.C.S.(E.), F.R.C.S.(Eng.) \\ Department of Orthopaedic Surgery, Hadassah University Hospital and Alyn Orthopaedic \\ Hospital ferusalem, Israel
}

IN the past few years, several reports have appeared dealing with epiphyseal displacements and fractures in children with spina bifida, usually emphasising the rarity of such complications (Soutter, I962; Carr, 1956; Golding, 1960). With the recent innovations in the treatment of spina bifida and childhood paraplegia in general, and the more active surgical approach applied (Ellison Nash, I957, I963; Sharrard, 1959), such fractures are becoming more common. Experience has shown that these are not all 'spontaneous' fractures (Katz, I953). To some extent the fractures are preventable, once their danger is realised. The purpose of this paper is to emphasise some of the preventable causes of such fractures.

Thirteen fractures occurred in seven children with paraplegia of various causes under our care during the years 1960-63. Six of these fractures were due to controllable factors and might have been prevented if the importance of these factors had been realised at the time.

Case I. S. H., aged I2, was admitted because of a complete paraplegia at the D8 level following transverse myelitis sustained at the age of two years. After reconstructive orthopaedic surgery had been carried out, and an ileal conduit had been fashioned, braces were fitted and the child began to walk independently for the first time with the aid of crutches. Two weeks later, after she had complained of malaise, it was noted that the child had a high fever $\left(40^{\circ} 3^{\circ} \mathrm{C}\right.$.). There was no history of injury. A swelling, with marked redness and all the signs of inflammation apart from tenderness, was noted over the upper third of the right tibia. Urine examination was negative. Leucocytes were 25,000/cu. $\mathrm{mm}$. X-ray showed a transverse fracture of the upper third of the tibia. In spite of this, because of the blatant signs of infection, exploration was carried out with a provisional diagnosis of acute osteomyelitis. No signs of infection were found at operation. A cast was applied and maintained for ten weeks, at which time clinical and radiological union were present. Four days after removal of the cast, a swelling was noted over the lower end of the same femur. Again there was no history of injury. X-ray showed a supracondylar fracture. During the four days, intensive passive movements had been afforded in order to mobilise the stiff paralysed limb. No fracture had been noted by the treating physiotherapist.

Case 2. N. R., aged ro years, underwent derotation osteotomy of the tibia for deformity secondary to his paraplegia, which was due to a myelomeningocele. After immobilisation for eight weeks, the cast was removed. Clinical and radiological union were present. Seven days later knee movement was still very limited and, therefore, self-assisted passive movements with the aid of a sling were instituted, in order to speed up remobilisation of the stiff knee. The child performed his movements so well that he refractured his anaesthetic paralysed limb at the osteotomy site at the first sitting.

Case 3. A. N., a traumatic paraplegic aged I4, rolled out of bed in an attempt to reach his braces. The fall was very light and from a height of less than $50 \mathrm{~cm}$. A supracondylar fracture ensued. One year later, in an identical accident, an identical fracture of the second femur occurred.

Case 4. S. R., aged 8, suffered from paraplegia due to a haemangioma of the cord in the mid-dorsal region. On admission a deep fistula led from a pressure sore over the 
right ischium. In order to facilitate healing after plastic repair of the ulcer and excision of the fistula, the child was immobilised in a spica for six weeks. Eight days after removal of the cast, swelling was noted over the right knee. The child admitted falling from bed two days previously, but as he had suffered no pain, he had not reported the fall. X-ray showed a displacement of the lower femoral epiphysis. The spica was replaced and maintained for a further eight weeks. Six days after removal of the second spica, a swelling was noted over the upper end of the tibia. No history of injury was obtainable this time, but intensive physiotherapy had been afforded to remobilise a very stiff knee. X-ray confirmed a fracture of tibia and fibula in their upper thirds (fig. I). The physiotherapist had not noticed any incident during treatment which might have been a fracture. Four weeks after removal of the cast necessitated by the tibial fracture, on the first day on which the child was allowed up from bed, a spontaneous supracondylar fracture of the femur developed on the side. Knee movement again was not completely free at this time, but it was considered safe enough to allow standing in braces. This once more was an error in judgment.

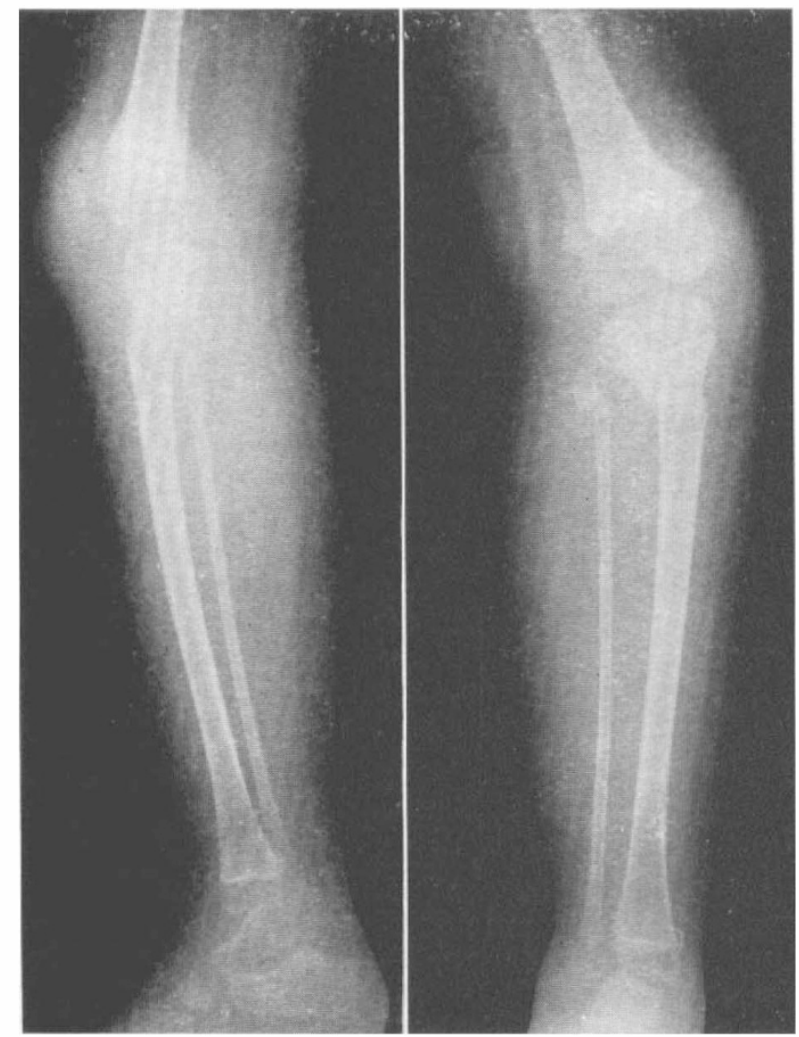

FIG. I

Six days after removal of cast necessitated by an epiphyseal displacement at the lower end of the femur, a fracture occurred in the upper third of the tibia. Periosteal new bone is seen in the region of the epiphysiolysis.

Case 5. Y. P., aged 6 years, with a myelomeningocele, was admitted with an incomplete paraplegia and with severe knee extension contractures, and bilateral paralytic 
hip dislocation. After a bilateral Sharrard procedure (Sharrard, I959) had been performed, with post-operative plaster immobilisation for ten weeks, the child was transferred to the urological department for the performance of an ileal conduit. In this unit, the physiotherapist was asked to continue mobilising the stiff joints. Two weeks after the urological operation, the physiotherapist informed the orthopaedic surgeon in charge that she had attained $90^{\circ}$ of knee movement on each side. Examination revealed marked thickening of the upper ends of the tibiae and X-ray revealed recent fractures on each side. The physiotherapist had not noticed any sudden change in 'knee movement' which might have suggested an acute fracture, nor was there any possibility of the child having fallen during this time.

Case 6. A. Z., aged 6, was admitted with a paraplegia secondary to a dorsal myelomeningocele. On examination there was some thickening of the left femur. X-ray revealed marked changes in the bony structure of the femur, resembling those of fibrous dysplasia (fig. 2). On previous X-rays becoming available, it was noted that there had been hyperplastic callus formation following a simple fracture of the femur three years previously (fig. 3). The 'fibrous dysplasia' was the result of incomplete resolution of the callus.

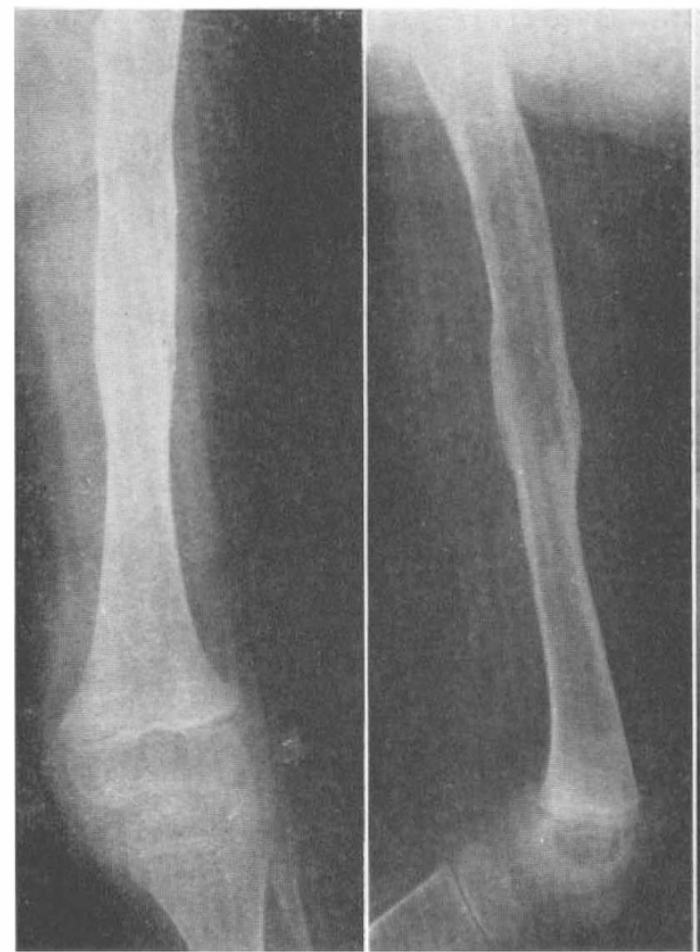

FIG. 2

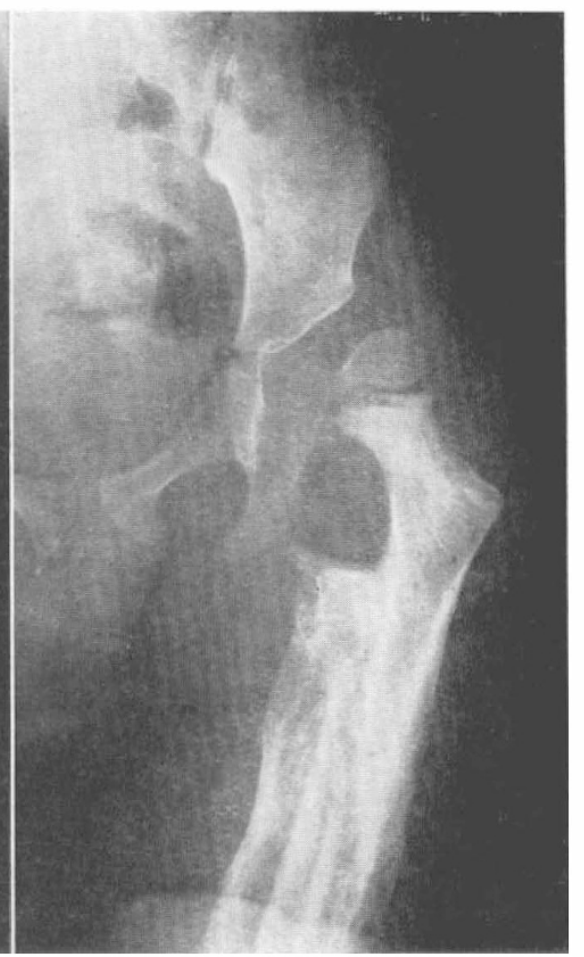

FIG. 3

Fig. 2. This X-ray shows the thickening of the shaft of the femur with a multilocular 'cystic' appearance of the bone, thought to be due to a localised fibrous dysplasia. Fig. 3. An X-ray of the same femur taken three years previously shows the oblique fracture of the upper part of the shaft of the bone with hyperplastic callus formation.

Case 7. I. C., a 5-year-old girl with a paraplegia due to an extensive lumbar myelomeningocele, underwent a bilateral Sharrard procedure and was immobilised in a 
plaster spica for Io weeks. Four weeks after removal of the cast she received braces and began to walk for the first time. Two days later, swelling of the left lower leg was noticed. An X-ray showed a fresh fracture of the lower third of the tibia and fibula and a healing fracture of the upper third of the tibia (fig. 4). There was no history of injury but intensive physiotherapy had been afforded from the time of removal of the cast, in order to remobilise the knees which were very stiff.

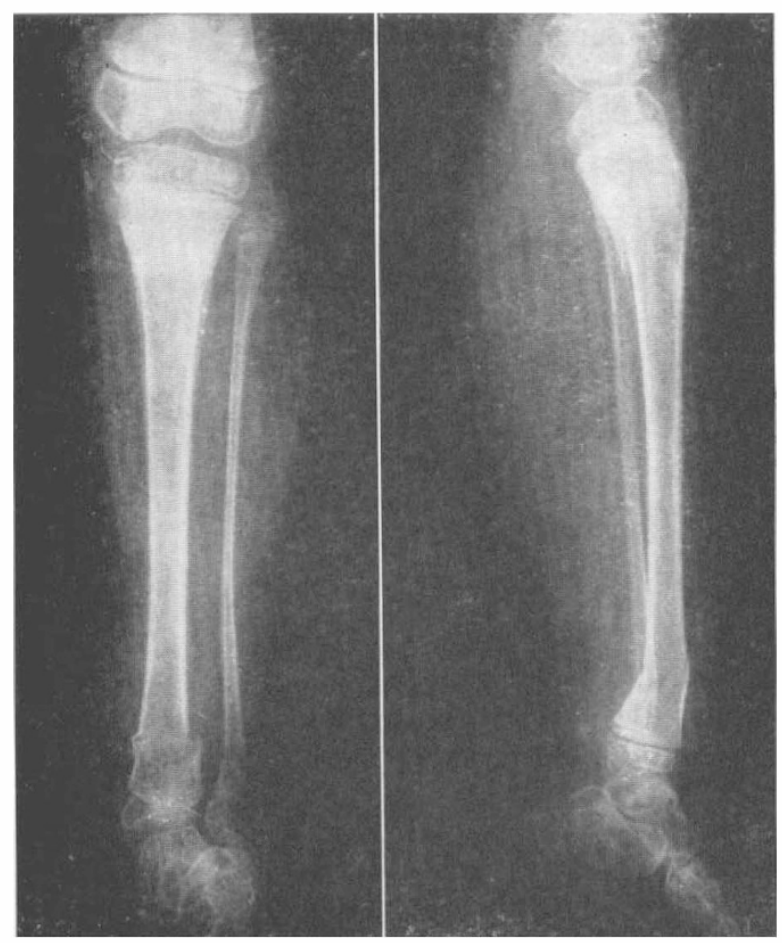

FIG. 4

A fresh fracture of the lower third of the tibia is present. In the upper third of the bone sub-periosteal new bone formation is seen at the site of an undisplaced stress fracture. Endosseous callus is also visible.

\section{DISCUSSION}

Among the thirteen fractures here described, most of the previously described phenomena in paraplegic fractures have been seen.

In Case I the first fracture resembles exactly those described by Soutter (1962), and like other cases, this girl was also operated upon with a diagnosis of osteomyelitis, in spite of knowledge of the presence of the fracture. Unfortunately, the fracture occurred exactly two weeks before Soutter's paper was published.

Hyperplastic callus described by Carr (1956) and by Gillies and Hartung (1938) was seen in Case 6. In the absence of an accurate history and without knowledge of the development of the bony changes it is not difficult to consider neoplastic change when confronted with the radiological picture shown here. Gillies and 
Hartung performed biopsy in one case with a provisional diagnosis of sarcoma, and we in fact considered biopsy before the previous X-rays became available.

The errors in diagnosis in our series together with those of previous authors confirm the difficulty sometimes experienced in such cases. The presence of anaesthesia makes the history often irrelevant since pain is never mentioned. Some fractures may not be noticed at the time of injury and the secondary effects of swelling and inflammation and systemic upsets such as fever may in fact be the presenting signs. In the presence of hyperplastic callus the swelling, the frequent low-grade fever and local heat and inflammation may easily present to the unwary a clinical picture of tumour.

However, the main purpose of this paper, as well as being a reminder of the unusual clinical and radiological pictures which may be met with in fractures in paraplegic childre $n$, is to emphasise the possibility of prevention of some of these fractures. Of the $\mathrm{I} 3$ fractures reported, seven occurred within a short time of removing casts necessitated by previous fractures or reconstructive surgery. On removal of these casts in paraplegic children, the problem of the stiff knee joint has to be faced. Hamstring and gastrocnemius paralysis completely prevent active remobilisation in these cases. This situation and its dangers have also been noted in patients with severe residual poliomyelitis and will be reported elsewhere, but the danger is especially prominent in these paraplegic children who are in addition anaesthetic, and have no 'pain-warning' sense. A vicious circle is often present. To leave the limb stiff invites further injury. The knee being stiff, there is no shock-absorber function at the joint and all the forces of even the slightest blow pass straight to the bone. The bone is frequently atrophic as the result of the paralysis, and is further atrophied as the result of immobilisation. On the other hand, too strenuous passive movements, as well demonstrated in Cases 2, 5 and 7, may give rise either to an acute fracture or to a stress type of fracture of incipient onset, which may be manifested at first only by an unnatural recovery of movement, and slight swelling. The swelling, in itself a natural sequel after removel of plaster, may not attract attention. The solution to this problem is not easy, entailing as it does the 'primrose path' between over-zealous and ineffective passive joint movement by the physiotherapist. The importance of the physiotherapist's understanding of the dangers must be emphasised.

The other factor involved in these fractures which is partly controllable is immobilisation osteoporosis and atrophy. Many surgeons have a tendency to set an 'average' time for union in a given fracture from the beginning, and examinations for the progress of union are dispensed with until the 'average time' is reached. In these cases examination for union should be carried out at the earliest possible time, and immobilisation dispensed with as soom as possible, since unnecessarily prolonged immobilisation can only further weaken the atrophic bone, and thus increase the likelihood of fracture. Furthermore, even if ambulation in cast is not always possible in these paraplegic patients, following operation or fracture, weight-bearing should be encouraged in the cast as soon as possible, again in an attempt to reduce immobilisation bone atrophy.

Moreover, once the cast has been removed, and until free knee movement has been regained, it is essential to keep the child in bed and not allow too much freedom, even in wheelchairs. The fact that I I of these I 3 fractures were close to the knee joint, five in the supra-condylar region and six at the upper end of the tibia, is in itself worthy of note. These sites are not common for fractures in childhood 
(Blount, I955), although Blount describes one such case in spina bifida, and Carr's single clinical description of one of the four fractures he mentions is also originally of a supracondylar fracture. Incidentally, they have been found to be very common sites for fracture in the paralysed limbs of children suffering from poliomyelitis (Robin, unpublished data) and in paraplegia in adults (Comarr, Hutchinson \& Bors, I962). This siting of the fractures would tend to confirm the presence of specific biomechanical factors related to stiffness of the knee joint, and emphasise the importance of remobilisation before free weight-bearing and ambulation are commenced. Certainly unguarded ambulation must be prohibited, even in braces. Considerable time may elapse until free joint movement is obtained, even with physiotherapy repeated several times a day, but only under such a régime can some of the fractures in paraplegic children be prevented.

\section{SUMMARY}

Thirteen fractures occurring in seven children suffering from paraplegia are described. The difficulties in diagnosis are briefly discussed. The temporal relationship between several of the fractures and plaster cast immobilisation is pointed out, and the possible relationship discussed. Methods of reducing the incidence of fractures in paraplegia children are suggested.

\section{RÉSUMÉ}

Treize fractures survenues chez sept enfants paraplégiques sont décrites. Les difficultés de diagnostic sont brèvement décrites. Les relations de temps entre plusieurs des fractures et leur immobilisation plâtrée est mentionnée ainsi que leurs corrélations possibles. Des méthodes, en vue de réduire l'incidence des fractures chez les enfants paraplégiques, sont suggérées.

\section{ZUSAMMENFASSUNG}

I3 Frakturen der langen Röhrenknochen bei 7 paraplegischen Kindern werden beschrieben. Diagnostische Schwierigkeiten werden erörtert. Es wird auf den zeitlichen Zusammenhang solcher Frakturen mit Gips-Ruhigstellung hingewiesen. Massnahmen für die Vorbeugung von Frakturen bei paraplegischen Kindern werden erwogen.

\section{REFERENCES}

Blount, W. P. (1955). Fractures in Children, p. 153. Baltimore: William \& Wilkins.

CARr, T. L. (I956). Postgrad. med. F. 32, $20 \mathrm{I}$.

Comarr, A. E., Hutchinson, R. H. \& Bors, E. (1962). Amer. f. Surg. 103, 732.

Ellison Nash, D. F. (1957). Ann. R. Coll. Surg. Engl. 29, 349.

Ellison Nash, D. F. (I963). Proc. R. Soc. Med. 56, 506.

Gillies, C. L. \& Hartung, W. (I938). Radiology, 31, 62 I.

Golding, C. (1960). F. Bone ft. Surg. 42B, 387.

Katz, J. F. (I953). F. Bone ft. Surg. 35A, 982.

RoBIN, G. C. To be published.

SHARRARD, W. J. W. (I959). F. Bone ft. Surg. 4IB, 662.

SOUTter, F. E. (1962). F. Bone ft. Surg. 44B, 106. 